\title{
THE INFLUENCE OF THE WAXY WHEAT FLOUR ON THE CAKE'S STALING
}

\author{
Kateryna lorgachova, Olga Makarova, Kateryna Khvostenko \\ Odessa National Academy of Food Technologies \\ 112, Kanatna Street, 65039 City of Odessa, Ukraine, \\ phone: +380958937043, e-mail: epinchuk@ukr.net
}

\begin{abstract}
Nowadays the use of waxy wheat in bread and pastry technologies, is gaining interest in view of extending the shelf-life of flour products, avoiding the use of additives. The obtained results shows the expediency of using waxy wheat flour, starch of which does not contain amylose, for the stabilization of the cake's quality during its storage. The influence of the mass fraction of non-amylose wheat flour on the physico-chemical and sensory characteristics of finished products were studied. Quality parameters like moisture content, rheological characteristics of the crumb, microbial and sensory analysis of developed products were evaluated during 7 days of storage period. It is found that replacement of bakery wheat flour with traditional starch content for the waxy wheat flour has the positive influence on the cake's staling process. These samples were characterized with lower decrease of moisture loss, less reduction of the amount of bound water in cake's crumb and higher organoleptic quality at the end of the shelf-life without adding of synthetic improvers.
\end{abstract}

Keywords: waxy wheat, flour, cake, quality, staling.

\section{INTRODUCTION}

Pastries are products of the daily diet of the population of Ukraine. Their assortment is wide enough and can satisfy modern consumer preferences. Also the trend of an annual increase in pastry production is observed on the flour product market [1]. Considering the fact that this group of products is gaining increasing popularity, improving the quality and extending the shelf life of pastry are among the most urgent tasks. As it is known, the provision of guarantee terms of storage and high taste characteristics of the product determine its competitiveness on the market.

At the moment, there are a number of methods for preservation and extension of shelf life of bakery and pastry products. These include the use of various ingredients that characterised with a high moisture holding capacity; adding of natural or synthetic origin improvers; selection of optimal technological parameters; freezing of semi-finished or finished products; adjustment of the baking parameters and cooling conditions of the products; using various packaging materials. All of the mentioned methods contribute to the increasing stability of the products, but they do not directly effect on the reason of consumer qualities deterioration of flour products.

According to the fact, that one of the main reason of flour products staling is retrogradation of starch-a process in which disaggregated amylose and amylopectin chains in a gelatinized starch paste reassociate to form more ordered structures [2], it is necessary to investigate the possibility of replacing flour with a traditional starch content with waxy wheat flour, starch of which doesn't contain amylose, which exercises a strong influence over the starch retrogradation process [3], for solving the problem of pastry staling without adding synthetic improvers. 


\section{IRTIIE

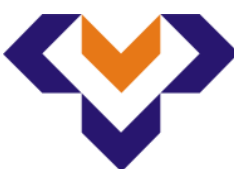

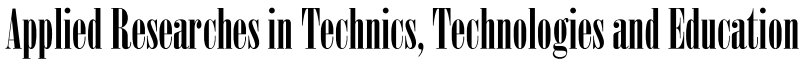 \\ Journal of the Faculty of Technics and Technologies, Trakia University https://sites.google.com/a/trakia-uni.bg/artte/}

Cakes, due to the variety of recipes and palatability, occupy a special segment in the market of flour products and are popular with consumers. Their quality mostly depends on the technological characteristics of the main raw material - wheat flour. Thus, the investigation of influence of the replacement of the traditional used bakery wheat flour for waxy wheat flour in the recipe of cake for their staling is necessary.

\section{METHODS}

The quality parameters of cakes during the storage period were studied by generally accepted methods in Ukraine [4].

Rheological characteristics of the crumb was measured as the peak compression force penetration rate $(P)$ during the penetratio of the sample.

Indicator method was used for the determination of the bound water amount. At the first stage, up to 5 grams of cake's crumb added $15 \mathrm{~cm}^{3} 10 \%$ solution of sucrose. Test sample was rubed for 5 minutes and was left for an $55 \mathrm{~min}$. Then the solution was filtered and the content of dry matter in the filtrate was determined. At the same time $15 \mathrm{~cm}^{3} 10 \%$ solution of sucrose was weighed and its concentration was checked.

The amount of bound water, $\mathrm{G}_{\mathrm{bw}}, \%$ to the total, was calculated according to the Eq. (1):

$$
G_{b w}=\frac{G * W}{100}+\frac{B *\left(b_{2}-b_{1}\right)}{b_{2}}
$$

G - sample mass, $\mathrm{g} ; \mathrm{W}$ - moisture content of the crumb, \%; B - solution of sucrose mass, $\mathrm{g}$; $b_{1}$ - initial dry matter of sucrose solution, $\% ; b_{2}$ - final dry matter of sucrose solution, $\%$.

For sensory evaluation, 20 panelists were selected (both males and females). The tests were performed under daylight room conditions. Sensory analyses were carried out on cakes samples based on flour with a traditional starch content (BWF) and waxy wheat flour (WWF). The appearance, texture and pore structure, taste-aroma and color of samples were rated on a 1-5 scale: 1 - dislike extremely; 2 - dislike slightly; 3 - neither like nor dislike; 4-like moderately; 5 - like extremely.

\section{EXPERIMENTAL AND RESULTS}

Cakes are a group of products, during the storage of which complex of physico-chemical processes occur due to partial retrogradation of starch and loss of moisture. In this period, the crumb becomes harder, dry and crumbly, the moisture content of the crust increases, the elasticity of both crust and crumb decrease, the ability to swell in water decreases, their microstructures change.

Cakes used in the study were stored for 7 days. Samples were packed in polyethylene packaging at temperature of $20 \pm 2{ }^{\circ} \mathrm{C}$ and a relative humidity of $60 \ldots 65 \%$.

It was found that adding of WWF leads to the decreasing of the moisture loss intensity in the product during storage. This index changes for samples based on BWF for $5,8 \%$ and for samples with WWF-for $3,0 \%$, accordingly. The obtained result, in our opinion, is due to the large content of pentosans in non-amylose waxy wheat flour [5] and the higher content of incomplete starch depolymerization products in cakes with WWF, which characterized by high hydrophilic properties. Also the branched structure of amylopectin, the main polysaccharide of the waxy wheat flour starch, prevent product's crumb from intensive migration of moisture.

One of the most obvious characteristics of freshness loss is an increase of product s crumb firmness. To measure it during storage, the rheological characteristics properties of the crumb were studed by the investigation of crumb`s compressibility - the penetration rate

IRITIE Vol. 6, No. 4, 2018 ISSN 1314-8788 (print), ISSN 1314-8796 (online), doi: 10.15547/artte.2018.04.012 
$(\mathrm{P})$. It is obtained that the compressibility of the crumb of all samples during storage decreased, but the use of WWF in the cake's technology was accompanied by fewer changes in their consistency. Obviously, such tendency occurs due to the lower temperature of gelatinization and the high autolytic activity of waxy wheat flour as compared to BWF [6]. As a result, the most starch molecules are destroyed during baking products with WWF. At the same time, the amount of non-hydrolyzed starch decreases, thereby reducing its degree of retrogradation, as the destroyed molecules are not able to unite in associates and form a crystalline phase, the presence of which leads to an increase of the crumb's products firmness and a decrease in their elasticity during storage.

The prolongation of the flour products freshness is most influenced by the strength of binding of moisture among its structural components. The process of redistribution of moisture occurred during the storage for all samples. After 7 days of storage the content of bound water in both samples decreased at different rates: in the control it was $11,2 \%$, whereas for the sample based on non-amylose wheat flour $-13,6 \%$. This shows the greater moisture binding strength among the structural components of the WWF cake sample.

To determine the cake's safety an analysis of microbiological indicators of products was performed at the end of the storage period according to the standarts.

Table 1. Microbiological indicators of cakes

\begin{tabular}{|l|c|c|c|}
\hline \multirow{2}{*}{ Analyzed parameter } & \multirow{2}{*}{ Standard } & \multicolumn{2}{|c|}{ Content } \\
\cline { 3 - 4 } & & \multicolumn{2}{|c|}{ Samples } \\
\cline { 3 - 4 } & 0,1 & 0,04 & WWF \\
\hline E.coli & $5 \times 10^{2}$ & $4,3 \times 10^{2}$ & $4,3 \times 10^{2}$ \\
\hline MAFAM, CFU/g, not more & 25 & 15 & 12 \\
\hline $\begin{array}{l}\text { Salmonella spp. / g, } \\
\text { not more }\end{array}$ & - & \multicolumn{2}{|c|}{ Not found } \\
\hline Yeast and mold, CFU/g & \multicolumn{2}{|c|}{} \\
\hline
\end{tabular}

According to the data of the microbiological indicators, it was found that cakes based on waxy wheat flour were characterized with microbiological purity at the final term of storage. Organoleptic characteristics of pastry are the main criterion that oriented the consumer. The texture of baked products effect on the sensory impression during its consumption and has a great influence on the perception of their quality during their shelf-life. Analysis of sensory evaluation show that samples with WWF had higher consumer characteristics compared with control. Products were characterized with higher volume, smooth surface, more elastic and less firm porous crumb at the end of storage term.

\section{CONCLUSIONS}

The obtained results show the feasibility of using non-amylose wheat flour for the stabilization of the cake's quality during their storage. The replacement bakery wheat flour on waxy sample leads to the positive influence on product quality characteristics. It has been established that the use of waxy wheat flour helps to slow down the loss of moisture, to decrease intensive change of crumb rheological characteristics, preserve the softer texture of the samples throughout the shelf life, which prove the effectiveness of using waxy wheat flour in cake technology for solving the problem of their staling without adding of synthetic improvers. 


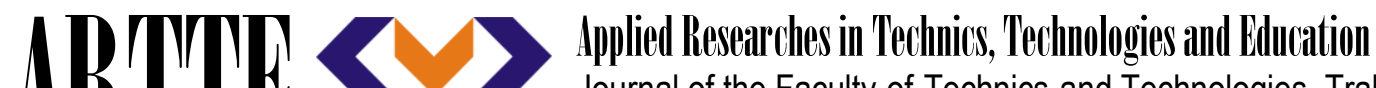 Journal of the Faculty of Technics and Technologies, Trakia University https://sites.google.com/a/trakia-uni.bg/artte/}

\section{REFERENCES}

[1] Ukraine: Market of the confectionary products. 2017. [Online]. Available: https://ukrprod.dp.ua/2017/11/10/ukraina-rynok-konditerskix-izdelij-2017-god.html.

[2] Shujun Wang, \& Caili Li, \& Les Copeland, \& Qing Niu, \& Shuo Wang (2015). Starch Retrogradation: A Comprehensive Review. Comprehensive Reviews in Food Science and Food Safety, Vol. 14 (2015), pp. 568-585.

[3] Sylvia Carolina, \& Maria Angela Almeida (2015). Physicochemical properties, modifications and applications of starches from different botanical sources. Food Science and Technology, Vol .35, No. 2, pp. 215-236.

[4] Iorgachova Kateryna, Makarova Olga, Gordienko Ludmila, Korkach Hanna (2011). Simeks-print, Odessa, (2011).

[5] Yu X. R., \& Zhou L., \& Zhang J. (2015). Comparison of structural development and biochemical accumulation of waxy and non-waxy wheat caryopses. Cereal Research Communications, Vol. 43, pp. 307-317.

[6] Rybalka Alexandr. Wheat quality and its improvement (2011). Logos, Kyiv, (2011). 